\title{
Sensitivity of Surface Urban Energy and Water Balance Scheme (SUEWS) to downscaling of reanalysis forcing data
}

Article

Accepted Version

Creative Commons: Attribution-Noncommercial-No Derivative Works 4.0

Kokkonen, T. V., Grimmond, C. S. B., Räty, O., Ward, H., Christen, A., Oke, T. R., Kotthaus, S. and Järvi, L. (2018) Sensitivity of Surface Urban Energy and Water Balance Scheme (SUEWS) to downscaling of reanalysis forcing data. Urban Climate, 23. pp. 36-52. ISSN 2212-0955 doi: https://doi.org/10.1016/j.uclim.2017.05.001 Available at https://centaur.reading.ac.uk/71089/

It is advisable to refer to the publisher's version if you intend to cite from the work. See Guidance on citing.

Published version at: http://dx.doi.org/10.1016/j.uclim.2017.05.001

To link to this article DOI: http://dx.doi.org/10.1016/j.uclim.2017.05.001

Publisher: Elsevier

All outputs in CentAUR are protected by Intellectual Property Rights law, including copyright law. Copyright and IPR is retained by the creators or other copyright holders. Terms and conditions for use of this material are defined in the End User Agreement. 


\section{CentAUR}

Central Archive at the University of Reading

Reading's research outputs online 
Kokkonen TV, CSB Grimmond, O Räty, HC Ward, A. Christen, T. R. Oke, S. Kotthaus, L Järvi Sensitivity of Surface Urban Energy and Water Balance Scheme (SUEWS) to downscaling of reanalysis forcing data Urban Climate, https://doi.org/10.1016/j.uclim.2017.05.001.

Sensitivity of Surface Urban Energy and Water Balance Scheme (SUEWS) to downscaling of reanalysis forcing data

T. V. Kokkonen ${ }^{\mathrm{a},{ }^{*}}$, C. S. B. Grimmond ${ }^{\mathrm{b}}$, O. Räty ${ }^{\mathrm{a}}$, H. C. Ward ${ }^{\mathrm{b}}$, A. Christen ${ }^{\mathrm{c}}$, T. R. Oke ${ }^{\mathrm{c}}$, S. Kotthaus $^{\mathrm{b}}$ and L. Järvi $^{\mathrm{a}}$

${ }^{a}$ Dep of Physics, University of Helsinki, P.O. Box 68, 00014 Helsinki, Finland *Corresponding author: tom.kokkonen@ helsinki.fi

${ }^{\mathrm{b}}$ Department of Meteorology, University of Reading, Reading, RG6 6BB, UK

${ }^{\mathrm{c}}$ Department of Geography, University of British Columbia, 1984 West Mall, Vancouver BC, V6T 1Z2, Canada

Keywords: urban hydrology, precipitation, land surface model, SUEWS, WFDEI, downscaling

\begin{abstract}
Often the meteorological forcing data required for urban hydrological models are unavailable at the required temporal resolution or for the desired period. Although reanalysis data can provide this information, the spatial resolution is often coarse relative to cities, so downscaling is required prior to use as realistic forcing. In this study, WATCH WFDEI reanalysis data are used to force the Surface Urban Energy and Water balance Scheme (SUEWS). From sensitivity tests in two cities, Vancouver and London with different orography, we conclude precipitation is the most important meteorological variable to be properly downscaled to obtain reliable surface hydrology results, with relative humidity being the second most important. Overestimation of precipitation in reanalysis data at the three sites gives 6-21\% higher annual modelled evaporation, 26-39\% higher runoff at one site and $4 \%$ lower value at one site when compared to modelled values using observed forcing data. Application of a bias correction method to the reanalysis precipitation reduces the model bias compared to using observed forcing data, when evaluated using eddy covariance evaporation measurements.
\end{abstract}

\title{
1. Introduction
}

Modelling urban water balance components, including evaporation and runoff, are crucial to understand, forecast and predict the hydrological cycle (including extreme events) in cities. With current global urban growth and development, there is increasing need for fine-scale hydrological information, particularly in areas where few or no routine observations exist, or under future urbanization scenarios.

The high fraction of impervious surfaces in urban areas generally increases surface runoff flow velocities and volumes and decreases infiltration and evaporation, all altering the probability of flooding (e.g. Rodriguez et al., 2003). High volumes of urban runoff impact water quality and hydrological regimes in local streams, inland waters and coastal zones, modifying ecological conditions and increasing the environmental burden (Knight and Cuffney, 2012; Konrad and Booth, 2002; Paul and Meyer, 2001). Detailed information is needed (e.g. from numerical models and/or from observational campaigns) in different macroclimates and city structures (e.g. city centre and suburban areas) to inform urban development. To undertake fine-scale urban hydrological modelling (Kanamitsu and Kanamaru, 2007; Wood, 2004) detailed, location-specific meteorological forcing data are required. High-resolution input data allow rapid changes in hydrological conditions (e.g. after a heavy rain event) to be explored. However direct observations of required variables to force urban climate and hydrological models are rare. Grimmond et al. (2010b) and the $5^{\text {th }}$ assessment report of the Intergovernmental Panel on Climate Change (IPCC, 2014) have highlighted the lack of urban observations and the need to have observations in a greater variety of locations. Due to the complexity and diversity of cities observational studies are typically limited to individual sites in a few cities.

Global reanalysis products can provide the essential variables to enable modelling where and when observations are unavailable (e.g. in data sparse regions of the world where cities are growing rapidly, or for past events before instruments were installed). Reanalysis data can also be used to supplement datasets that are missing required variables, or to provide higher temporal resolution data if only coarse information is available (e.g. daily totals). Reanalysis data are generated by rerunning global meteorological models but with data assimilation of a large amount of observations (e.g. remote sensing and ground based observations). Although there are a number of reanalysis products available (e.g. ERA-Interim (Dee et al., 2011), MERRA (Rienecker et al., 2011), JRA-55 (Kobayashi et al., 2015), NCEP (Kalnay et al., 1996), WFDEI (Weedon et al., 2014)), they are typically spatially coarse (e.g. $0.5^{\circ}$ ). This means that downscaling is needed prior to use for local-scale urban hydrological modelling (Bastola and Misra, 2014; Fowler et al., 2007; Wilby et al., 2000). For example, large variations in topography can cause the mean grid height of the reanalysis product to be different from the height of the study site (Frei et al., 2003). As the finescale distribution of precipitation is highly dependent on orography (e.g. Brunsdon et al., 2001; Oke and Hay, 1994), accounting for it may be crucial for reliable model results (e.g. Bastola and Misra, 2014). Convection-resolving numerical weather prediction allows precipitation distributions to be modelled (Brisson et al., 2016) but requires a large amount of computer resources for climate runs. Although this method has the advantage of not requiring a priori observations for application, convection-resolving modelling is an area of active research because of the many challenges with cloud processes relative to the grid size (Holloway et al., 2014).

To reduce the computational needs for applications, bias correction with quantile mapping (BCQM) has been found to be an effective method to correct daily precipitation intensities in climate projections (e.g. Gudmundsson et al., 2012; Räty et al., 2014; Sunyer et al., 2015; Teutschbein and Seibert, 2012). Although this method has the disadvantage of requiring observations to undertake the corrections, it does retain the observed distributions as a constraint. As the temporal resolution of reanalysis products is typically 3 to $6 \mathrm{~h}$, i.e. too coarse for detailed hydrological modelling (Bastola and Misra, 2014), interpolation to finer temporal resolution is needed. To date, reanalysis products have been little used in the modelling of urban water and energy 
exchanges. As the WATCH WFDEI reanalysis data (Weedon et al. 2011, 2014) are specifically derived for hydrological modelling from ERA-Interim, and have been used to model surface energy fluxes in 20 different urban areas (Best and Grimmond 2016), they are chosen for this study.

There are a large number of urban land surface models (Grimmond et al., 2009) that take a wide variety of approaches to describing urban surface exchange processes (Grimmond et al. 2010a, 2011). Given the importance of vegetation to urban hydrology and turbulent exchange (Best and Grimmond, 2014, 2016) and its significant presence in suburban areas and central business districts it is critical that a scheme can simulate its influence on the surface energy and water balances (Best and Grimmond, 2013, 2014; Grimmond et al., 2011; Loridan and Grimmond, 2012; Nordbo et al., 2015). Where many gardens and parks are present, irrigation can become an important component of the local water balance (Grimmond and Oke, 1986; Mitchell et al., 2001, 2003) thereby also influencing energy exchange.

The urban land surface model used in this study is the Surface Urban Energy and Water balance Scheme (SUEWS). This local (neighbourhood) scale scheme can simulate both energy and water balance components (Järvi et al., 2011, 2014; Ward et al., $2016 \mathrm{~b}$ ) including vegetation and irrigation but, is simple enough to handle multiple grids and several years without special computational power. It requires only basic meteorological data and surface information as inputs. With the procedures described in this paper, SUEWS can be run with limited local observations by using reanalysis data as forcing.

The objective of this study is to assess the impact of reanalysis forcing data on the performance of an urban land surface and water balance model in two cities: Vancouver, Canada, and London, UK (Section 2.1). To force the model (SUEWS, Section 2.2) the WATCH WFDEI (Weedon et al., 2014) reanalysis data (Section 2.3) are used. The precipitation reanalysis data are corrected to improve the spatial representativeness of the data for the study area relative to the WFDEI grid box (Section 2.3.1). First the sensitivity of the model to the required meteorological data is examined (Section 3.1), second the effect of bias correction to precipitation is examined (Section 3.2) and third the performance of SUEWS running with reanalysis data is examined (Section 3.3). The model output using both observed and reanalysis data (both corrected and uncorrected) as forcing are compared against evaporation measured with the eddy covariance technique at one site in both Vancouver and London. The consideration of multiple sites in different cities allows different urban land covers and weather patterns to be considered. Although, errors in model performance can arise from model parameterizations, this is the focus of other papers (e.g. Alexander et al. 2016, Karsisto et al. 2015, Ward et al. 2016b) and not specifically addressed here.

\section{Methods}

\subsection{Study areas and sites}

Vancouver and London both experience maritime temperate climates (Met Office, 2016; Oke and Hay, 1994). The more topographically diverse Vancouver (Figure 1) has an enhancement of $100 \mathrm{~mm}$ annual precipitation per $100 \mathrm{~m}$ increase in elevation (Oke and Hay, 1994). Near sea level, precipitation is approximately $900 \mathrm{~mm} \mathrm{y}^{-1}$ (South Richmond) whereas the nearby mountains record over $3500 \mathrm{~mm} \mathrm{y}^{-1}$ (Hollyburn $1326 \mathrm{~m}$, Grouse $1231 \mathrm{~m}$ ). Winter precipitation is approximately four times greater than in summer (Figure 2; Oke and Hay, 1994).

The study sites in Vancouver are two suburban neighbourhoods, "Vancouver-Oakridge" and "Vancouver-Sunset" (Table 1), that are approximately $3 \mathrm{~km}$ apart on a fairly flat terrain (Figure 1). The annual precipitation at both areas is approximately $1000 \mathrm{~mm}$ $\mathrm{y}^{-1}$ (Environment Canada, 2015). The two residential areas have 1-2 storey single-family dwellings (LCZ 6, Stewart and Oke, 2012), but differ in their characteristic lot and building size and land cover (Table 1). The impervious surface cover fraction is larger in the more densely populated area Vancouver-Sunset (68\%, almost three times as many inhabitants) than in VancouverOakridge (44\%) (Table 1). In addition, the amount and area of irrigation varies between the sites further affecting the local water balance.

London is occasionally influenced by continental weather that brings cold spells in winter and hot and humid weather in summer (Met Office, 2016). The mean annual rainfall in central London is $570 \mathrm{~mm} \mathrm{y}^{-1}$ (St. James's Park meteorological station for 19801999, see Section 2.3.1; Met Office, 2015). This rainfall, generally, is evenly distributed through the year (Figure 2), with significant amounts of showery convective rainfall in the summer. The focus of this study is the central business district of Westminster (Figure 1). There are extensive impervious surfaces (81\%) with little vegetation (5\%, Table 1) but with insignificant irrigation. The area has a large daytime population and a high volume of traffic (Greater London Authority, 2015) making anthropogenic heat fluxes important (Ward et al., 2016b, 2017).

Forcing and evaluation data are available from observations in both cities. Modelled evaporation is compared with the eddy covariance (EC) observations at Vancouver-Sunset (Christen et al., 2011) and London (Kotthaus and Grimmond, 2014a, b). At both sites, sonic anemometers (CSAT3 Campbell Scientific) with open path infrared gas analysers (Li-7500 Licor Inc.) are used. Other measured variables needed for model forcing include incoming shortwave radiation $K \downarrow$, precipitation $P$, air temperature $T_{a}$, station pressure $p$, relative humidity $R H$, and wind speed $U$. At Vancouver-Oakridge, no EC observations were available. The meteorological observations used as model forcing are described in Grimmond and Oke (1986).

Long-term observations of daily precipitation needed for a calibration period of the reanalysis data correction (Section 2.4.1) were made with tipping bucket rain gauges at Vancouver-Oakridge (1990-2008) (Environment Canada, 2015) and St. James's Park (1980-1999) (Met Office, 2015). These long-term observations are available with a daily resolution, whereas the on-site 
measurements are averaged to $1 \mathrm{~h}$ resolution. The relative locations of the long-term measurements, the site-specific measurements and the reanalysis grid are shown in Figure 1 for both Vancouver and London.

\subsection{SUEWS model overview}

In this study, version V2016a of the Surface Urban Energy and Water balance Scheme (SUEWS) is used (Ward et al., 2016a). The model is run with a 5-min time step to capture rapid changes in the water balance, for example in a convective rain event. SUEWS primary spatial scale corresponds to that used in planning and design related to land use, land cover and infrastructure in cities (Kellett et al., 2013). Physical processes (e.g. evaporation, interception) are modelled for seven surface types (paved, buildings, evergreen trees/shrubs, deciduous trees/shrubs, grass, bare soil and water). In SUEWS, the water state of each surface is calculated from a running water balance accounting for evaporation, runoff and drainage (Grimmond and Oke, 1991). Below each surface type, except water, there is a single soil layer. The fluxes calculated for an individual time step are a function of the proportion of the component surface types in the area. The net change in water storage is determined from the combined changes in surface states and soil moisture.

Model performance in terms of urban hydrology has been found to be largely dependent on the impervious water storage formulation and parameters (Wouters et al., 2015). The net all-wave radiation is simulated using the net all-wave radiation scheme (NARP; Loridan et al., 2011; Offerle et al., 2003) and storage heat flux using the Objective Hysteresis Model (OHM, Grimmond et al., 1991). Anthropogenic heat flux is calculated based on heating and cooling degree-days, assuming a base temperature of $18.2{ }^{\circ} \mathrm{C}$ above which cooling and below which heating of the buildings takes place (Järvi et al., 2011). Latent heat flux (evaporation) is calculated using the modified Penman-Monteith equation and sensible heat flux is taken as the residual from the other energy balance components. During each 5-min time step, the surface and soil water storages, water movements between the storages and surface runoff are calculated. The model needs meteorological data (section 2.1) and information about the cover fractions of the seven surface types, tree and building heights and population density (Table 1).

\subsection{Reanalysis data and corrections}

Similar to Best and Grimmond (2016), the WATCH Forcing Data ERA-Interim (WFDEI) (Weedon et al., 2014) are used to derive the model forcing data. The WFDEI dataset is derived for hydrological modelling purposes from the ERA-Interim reanalysis product (Dee et al., 2011) via sequential interpolation to half-degree spatial resolution with $3 \mathrm{~h}$ temporal resolution. WFDEI includes two precipitation datasets with different bias corrections: Climatic Research Unit's CRU TS3.101 (Harris et al., 2013) and Global Precipitation Climatology Centre's GPCCv5 (Schneider et al., 2013). In this study, GPCC data are used for the better station density. Only stations on land area are used for precipitation estimations.

The WFDEI data are interpolated from $3 \mathrm{~h}$ to $1 \mathrm{~h}$ (default for SUEWS) resolution. WFDEI average rainfall for the previous $3 \mathrm{~h}$ $\left(\mathrm{kg} \mathrm{m}^{2} \mathrm{~s}^{-1}\right)$ is converted to $\mathrm{mm} \mathrm{h}^{-1}$ by assuming the rain rate is constant for the period. Given the focus on the long-term water balance this is taken as reasonable. In both Vancouver and London most precipitation is from frontal rain, although London experiences showery convective rain in summer months. London also has considerable contribution from stratiform clouds often lasting for a day or longer. Specific humidity $(q), p$ and $T_{a}$ are linearly interpolated from $3 \mathrm{~h}$ to $1 \mathrm{~h}$. $K \downarrow$ is interpolated to $1 \mathrm{~h}$ using a method that takes into account its strong diurnal cycle which otherwise would cause issues around sunrise and sunset. Figure 3 shows WFDEI $K \downarrow$ compared to the observations at Vancouver and London sites. The observations in Vancouver-Oakridge are in apparent time while the WFDEI data are in local time, so there is a small time shift between the data and thus are not fully comparable at hourly resolution. As the correlation is very good ( $\mathrm{r}>0.91$, RMSE $<92 \mathrm{~W} \mathrm{~m}^{-2}$ ), $K \downarrow$ is used without any additional corrections. In addition, the timestamp of the WFDEI data is changed from UTC to local time of the site.

The WFDEI grid height is the areally weighted mean height of the topography in each grid. In Vancouver, with mountains in the north (Figure 1), the grid height is $213 \mathrm{~m}$ above sea level (asl), whereas in London it is $78 \mathrm{~m}$ asl. The appropriate simulation height needs to consider the land elevation of the area of interest, the height of the roughness elements (buildings, trees) and the appropriate height for the forcing data for the simulation (e.g. height of evaluation observations if undertaking a comparison). The simulation heights used are $106 \mathrm{~m}$ asl for Vancouver-Sunset, $113 \mathrm{~m}$ asl for Vancouver-Oakridge, and $61 \mathrm{~m}$ asl for London.

The WFDEI $T_{a}$ and $p$ are adjusted to the simulation height using environmental lapse rate $\left(\Gamma=-6.5^{\circ} \mathrm{C} \mathrm{km}^{-1}\right)$ and the hypsometric equation (Weedon et al. 2010). $R H$, used by SUEWS, is calculated from the WFDEI specific humidity assuming it is constant with altitude to avoid supersaturation.

Interpolation requires a spin up period to avoid interpolation errors and missing data points at the beginning and at the end of the time series. Here, periods of one month before and after the main study periods are used.

\subsubsection{Bias correction of the precipitation}

Bias correction with quantile mapping (BCQM) following Räty et al. (2014) and Räisänen and Räty (2013, see their Figure 5) is used to adjust daily precipitation towards the observed precipitation. In addition to mean precipitation the method corrects the spread and shape of the daily precipitation distribution. In the process (Figure 4) the data are brought to $1 \mathrm{~h}$ temporal resolution using the relation between the uncorrected and BCQM-corrected WFDEI precipitation. 
Quantile mapping techniques create a one-to-one mapping between two cumulative distribution functions of reanalysis data and observations (Sun et al., 2011). Cumulative distribution functions of the observed $\left(F_{o}\right)$ and WFDEI $\left(F_{c}\right)$ daily precipitation are first estimated for a calibration period (1990-2008 in Vancouver, 1980-1999 in London). Long calibration periods, typically in the order of 30 years (e.g. Dosio and Paruolo, 2011), are suggested in order to take decadal climate variability into account (e.g. Piani et al., 2010). BCQM transforms the whole reanalysis precipitation time series $\left(s_{i}\right)$ into the bias corrected one $\left(P_{i}\right)$ according to:

$$
P_{i}=F_{o}^{-1}\left(F_{c}\left(s_{i}\right)\right) \text {. }
$$

Before the transformation, $F_{o}^{-1}$ and $F_{c}^{-1}$ are smoothed by taking a running mean over a range of quantiles to reduce noise, particularly in the upper tail of the distribution. For example, the smoothed quantiles for the reanalysis data in the calibration period $\left(F_{c}^{-1}\right)$ are obtained as

$$
F_{c}^{-1}(x)=\frac{\int_{\max (x-a, 0)}^{\min (x+a, 1)} F_{c}^{-1}(x) d x}{\int_{\max (x-a, 0)}^{\min (x+a)} d x},
$$

where $x \in[0,1]$ and $a$ is the smoothing parameter, giving the range of quantiles over which smoothing is applied. Räty et al. (2014) recommend a small value for $a$, as the smoothing tends to contract the distribution, making the correction less accurate in the upper tail (i.e. extremely intense precipitation). After sensitivity tests (see Section 3.2), $a$ is set to 0.04 for Vancouver and 0.00 (no smoothing) for London. This means that, for example, $\tilde{F}_{c}^{-1}(1)$ in Vancouver equals the mean of the highest $4 \%$ of the precipitation in the calibration period.

If values of the full WFDEI time series are outside of the range of values in the calibration period, there is a need for extrapolation in the quantile-quantile relation. In this case, bias corrected values are obtained assuming constant relative change above the maximum of the calibration period distribution.

The reanalysis precipitation values are adjusted separately for each day of year using BCQM. To further reduce the effect of noise in the estimation of biases, a linear moving window (width $W$ ), centred around the day under consideration, is used to increase the amount of data used in assessing biases. After sensitivity tests (see Section 3.2), $W$ is set to 51 for Vancouver and 61 for London. Note, parameter values $a$ and $W$ are not universal, so different values might be optimal in other cases.

SUEWS is designed to run with input data at $1 \mathrm{~h}$ resolution. However, due to observational constraints, precipitation is bias corrected at daily temporal resolution. Assuming that the within-day temporal variability is approximately captured by the WFDEI dataset and that hourly precipitation intensities have similar biases within a day. The corrected hourly values are obtained by simply adjusting the hourly precipitation intensities with a constant factor defined by the relation between daily uncorrected and BCQM-corrected WFDEI precipitation. Although these assumptions are rather strong, they should provide reasonable results at seasonal and annual scales, which are the main interest in this study.

\subsection{Experimental outline}

The SUEWS model (Section 2.2) runs are made using hourly, locally measured data (Section 2.1) (hereafter the control run) and WFDEI reanalysis data (Section 2.3) as a forcing. The latter includes both quantile mapping bias corrected (BCQM) (Section 2.3.1) and uncorrected WFDEI data. The sensitivity of the model to the reanalysis data is examined by changing each variable in the measured forcing data to the reanalysis data independently.

The SUEWS model performance is evaluated by comparing model outputs against observed evaporation. All runs at each site, whether using measured or reanalysis forcing data,have the same surface and population information. Surface cover fractions, building and tree heights, initial conditions and other parameter values are adapted from Järvi et al. (2011) for the Vancouver sites and from Ward et al. (2016b) for London (Table 1).

For London and Vancouver-Sunset a full year is simulated (2012 and 2009, respectively) for the EC footprint area and Vancouver-Oakridge is simulated for 22 January 1982 - 21 January 1983 for the water monitoring area (Grimmond and Oke, 1986). This will be referred as the study year. Hereafter the sites are referred to as Lo12, Vs09 and Vo82, respectively.

\section{Results and discussion \\ 3.1 The sensitivity of SUEWS to its forcing data}

To identify the meteorological variables SUEWS is most sensitive to, and therefore should be corrected, each input variable is independently examined. SUEWS is run with observed forcing data systematically replacing each variable with the WFDEI equivalent. To assess this, the simulated cumulative evaporation and runoff using the different combinations of forcing data are compared to the control run at each of the three studied sites.

In Vancouver, using most of the input WFDEI variables results in a higher total evaporation and runoff compared to the control run (Table 3). Only four variables in Vo82, and two variables in Vs09, give slightly smaller totals of evaporation (1-4 \%) and two variables give slightly smaller totals for runoff (1-4\%) at both sites in Vancouver. In London, however, more variation occurs with the different input combinations. In London two of the WFDEI variables gives smaller totals of evaporation (2-9\%) and four variables gives smaller totals of runoff (1-7\%). At all three sites, precipitation has the largest impact on simulated evaporation and runoff when compared to the other meteorological variables (Figure 5). Changing the observed precipitation to WFDEI precipitation increases the modelled cumulative evaporation by $18 \%$ in Vo82, $26 \%$ in Vs09 and $14 \%$ in Lo12 when compared to the control run (Figure 5a, c, e). 
Non-gap-filled EC measured evaporation rates for Vs09 (6961 h) and Lo12 (5598 h) allow direct assessment for the hours when observations are available (Figure 6, Table 4). When compared directly to the observed evaporation, the totals are $5 \%$ and $46 \%$ higher in Vs09 and Lo12, respectively, when using the WFDEI precipitation as opposed to the observed forcing data. The RMSEs are $0.0444 \mathrm{~mm} \mathrm{~h}^{-1}$ for $\mathrm{Vs} 09$ and $0.0382 \mathrm{~mm} \mathrm{~h}^{-1}$ for Lo12 (87\% and $114 \%$ of average hourly observed evaporation, respectively) when compared to direct observations.

As no observed runoff data are available the control runs are used as the reference. For runoff, changing from observed to WFDEI precipitation gives higher values by $27 \%$ in Vo82 and $39 \%$ in Vs09 and a lower value by $7 \%$ in Lo12 (Figure 5b, d, f).

When observed RH and RH derived from WFDEI are compared the correlations and percentages of hourly RMSEs of average hourly observed RH are 0.71 and $15 \%$ in Vo82, 0.78 and $15 \%$ in Vs09 and 0.88 and $9 \%$ in Lo12, respectively. The deviation in RH impacts the modelled evaporation directly. When the observed RH is replaced with RH derived from WFDEI there is a difference in model results of 3-9\% on cumulative evaporation at the three sites. There is an increase of $8 \%$ in Vo82, $3 \%$ in Vs09 and a decrease of $9 \%$ in Lo12 when compared to the control run. The cumulative modelled values underestimate by $17 \%$ in Vs09 relative to the EC observations but overestimate (14\%) in Lo12. The hourly RMSE is $0.0367 \mathrm{~mm} \mathrm{~h}^{-1}$ in $\mathrm{Vs} 09$ and 0.0296 $\mathrm{mm} \mathrm{h}^{-1}$ in Lo12 (74 \% and $88 \%$ of average hourly evaporation, respectively). For Lo12, the lower values of evaporation when WFDEI RH is used actually balances the higher values due to precipitation and brings the values closer to the modelled evaporation of the control run when all of the WFDEI variables are used to force the model (see Section 3.3). The impact on runoff of changing the observed RH to RH derived from WFDEI is small: a decrease of $2 \%$ in Vo82 and $1 \%$ in Vs09 and an increase of $2 \%$ in Lo12 compared to the control run.

Other WFDEI variables $\left(U, T_{a}, K \downarrow\right.$ and $p$ ) have minor influence on mean $1 \mathrm{~h}$ modelled evaporation and runoff. The difference in total annual evaporation ( $\mathrm{Vs} 09, K \downarrow)$ and runoff $\left(\mathrm{Vs} 09, T_{a}\right)$ are up to $4 \%$ when each measured variable in the forcing is changed to its respective WFDEI variable. Alexander et al.'s (2015) sensitivity study of SUEWS to $U, T_{a}$ and $K \downarrow$ in Dublin, Ireland found $K \downarrow$ to have the greatest impact but still insignificant. Thus, SUEWS is rather insensitive to minor errors in these meteorological variables at the studied sites. Although RH has a significant effect on the model results it is substantially less than the effect of precipitation, so it is less critical to correct $U, T_{a}, K \downarrow, \mathrm{RH}$, and $p$ in similar matter as precipitation in the WFDEI forcing data.

For SUEWS' performance, realistic precipitation is most critical.

\subsection{The effect of bias correction to precipitation}

As the WFDEI precipitation clearly overestimates observed precipitation especially in Vancouver (Figure 2), which leads to higher values of evaporation (Figure 5) compared to the control run, the precipitation is bias-corrected with quantile mapping to bring it closer to the observed values.

Effects of varying the BCQM smoothing parameter $(a)$ and moving window $(W)$ for each site on SUEWS modelled evaporation (compared to EC observations) are very small (Table 2). The modelled evaporation is assessed with the root mean square error (RMSE) using hourly data. Varying the smoothing parameter $(a)$ from 0.00 to 0.05 caused the RMSE of the modelled evaporation in Vs09 to vary between $0.0352-0.0353 \mathrm{~mm} \mathrm{~h}^{-1}$ (69\% of average hourly observed evaporation) and in Lo12 $0.0363-0.0364$ (108 $\%$ of average). The absolute differences of the modelled annual evaporation are $5 \%$ and $31 \%$ of observed annual total evaporation in Vs09 and Lo12, respectively.

Varying the moving window $(W)$ from 21 to 71 days caused the modelled evaporation are very similar to those for $a$ : for Vs09 RMSE varies between $0.0352-0.0355 \mathrm{~mm} \mathrm{~h}^{-1}\left(69 \%\right.$ of average hourly evaporation) and for Lo12 $0.0364-0.0365 \mathrm{~mm} \mathrm{~h}^{-1}(108 \%$ of average). The absolute differences of the modelled annual evaporation are 4-5\% and $31 \%$ of observed annual total evaporation in Vs09 and Lo12, respectively.

Figure 7 shows that the WFDEI daily precipitation distribution is effectively corrected to match the observed distribution of precipitation, except for the most extreme precipitation values where differences are still noticeable. This is probably related to sampling noise in the extreme upper tail of the precipitation distribution and to uncertainties in the extrapolation procedure.

As a result of BCQM correction the annual cumulative precipitation decreased from 1943 to $1479 \mathrm{~mm} \mathrm{y}^{-1}$ in Vo82, from 1739 to $1346 \mathrm{~mm} \mathrm{y}^{-1}$ in Vs09 and from 859 to $834 \mathrm{~mm} \mathrm{y}^{-1}$ in Lo12, bringing it closer to observed precipitation (1215 $\mathrm{mm} \mathrm{y}^{-1}$ in Vo82, $1295 \mathrm{~mm} \mathrm{y}^{-1}$ in Vs09 and $821 \mathrm{~mm} \mathrm{y}^{-1}$ in Lo12) at all three sites. The BCQM correction works reasonably well for Vs09 and Lo12, but there is still quite large overestimation of precipitation left in Vo82. This might be partly due to the differences in the observations. The on-site observations are at $1 \mathrm{~h}$ resolution, whereas the long-term observations used for BCQM corrections are at daily resolution and from different locations than the site-specific observations (see Section 2.1). The assessment of biases at daily level using a moving window might introduce artificial biases and differences that might be relatively large when comparing against single year. This underlines the importance of high quality observations for the robust calibration and validation of bias correction methods.

The BCQM corrected precipitation replaced in otherwise observed forcing data decreases the cumulative evaporation by $4-15 \%$ when compared the evaporation given with uncorrected WFDEI precipitation, bringing the values closer to the control run, resulting in higher values of $10 \%$ in Vo82, $11 \%$ in Vs09 and $10 \%$ in Lo12. When compared to the direct observations of evaporation the change of uncorrected WFDEI data to the BCQM corrected precipitation increases the difference by $4 \%$ in Vs09 
and decreases the difference by $6 \%$ in Lo12; resulting in underestimation of $9 \%$ and overestimation of $40 \%$, respectively. However, the hourly RMSE with BCQM corrected precipitation is better than with uncorrected WFDEI precipitation at both sites when compared to the direct observations: $0.0396 \mathrm{~mm} \mathrm{~h}^{-1}$ in Vs09 and $0.0367 \mathrm{~mm} \mathrm{~h}^{-1}$ in Lo12 (77\% and $109 \%$ of average hourly evaporation, respectively).

When the BCQM corrected precipitation is used with the observed forcing data the difference in runoff decreases by $0-20 \%$ compared to the difference with uncorrected WFDEI precipitation, resulting in differences of $10 \%$ in Vo82, $19 \%$ in Vs09 and -7 $\%$ in Lo12 when compared to the control run.

\subsection{Effect of WFDEI forcing data on SUEWS performance}

Subsequent model runs use both uncorrected and BCQM corrected WFDEI precipitation while WFDEI values are used for other variables. The simulated evaporation using uncorrected WFDEI as model forcing is larger than for the control run (Figure 5a, c, e) following the overestimated precipitation in WFDEI (Figure 2). The annual cumulative evaporation is $15 \%$ higher in Vo82, $21 \%$

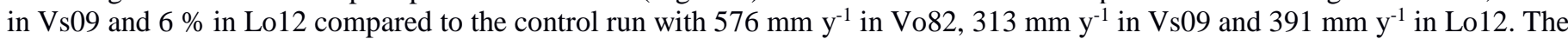
difference is much larger at the two Vancouver sites than in Lo12 due to the larger overestimation in precipitation (caused by the close proximity of mountains that affects the grid height of WFDEI, see Section 2.3). Although the BCQM correction to precipitation decreases the bias when compared to the control run, the overestimation of the precipitation is still evident. After the BCQM correction the annual cumulative evaporation with WFDEI forcing data is $8 \%$ higher in Vo82, $6 \%$ in Vs09 and $2 \%$ in Lo12.

The WFDEI forcing data follows closely the runoff of the control run in Lo12 (Figure 5f), but similarly to evaporation, the modelled runoff using uncorrected WFDEI data in Vancouver gives largely higher values compared to the control run (Figure 5b, d). Use of the uncorrected WFDEI gives higher values of the annual cumulative runoff by $26 \%$ in Vo82 and $39 \%$ in Vs09, but gives lower values by $4 \%$ in Lo12, when compared to the control run (1819 $\mathrm{mm} \mathrm{y}^{-1}$ in Vo82, $1426 \mathrm{~mm} \mathrm{y}^{-1}$ in Vs09 and $577 \mathrm{~mm} \mathrm{y}^{-}$ ${ }^{1}$ in Lo12). BCQM correction brings the modelled runoff significantly closer to the reference values in Vancouver resulting in a smaller increase of $8 \%$ in Vo82 and $15 \%$ in Vs09. In Lo12, the difference increases by $1 \mathrm{~mm}$ to $26 \mathrm{~mm} \mathrm{y}^{-1}(4 \%)$ after the BCQM correction. Thus, the relative change caused by the correction is larger in Vancouver than London as the difference is not as great initially when compared to the Vancouver sites.

The directly measured hourly EC evaporation allow for assessment of the modelled evaporation (Figure 6). In Vs09 the modelled

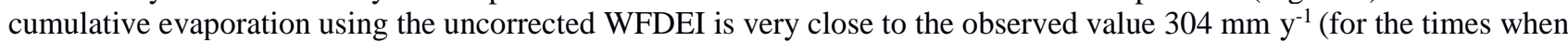
observations are available), with an underestimation of $3 \%$. The BCQM correction increases this underestimation to $15 \%$. The underestimation is greater $(18 \%)$ when measured forcing data are used. Although the underestimation of modelled cumulative evaporation increases, the BCQM correction decreases the hourly RMSE between the measured and modelled evaporation from 0.0398 to $0.0354 \mathrm{~mm} \mathrm{~h}^{-1}$ (78 \% to $69 \%$ of average hourly evaporation, respectively) bringing it very close to the RMSE of the control run $\left(0.0369 \mathrm{~mm} \mathrm{~h}^{-1}, 72 \%\right.$ of average). The BCQM correction is not expected to make the model results perfect relative to the observations as differences will remain related to parameterisations within SUEWS. As urban land surface models tend to underestimate vegetative evaporation (Grimmond et al. 2010a, 2011), the larger underestimation is likely linked to the description of evaporation in SUEWS rather than the forcing data itself. In addition to vegetation, the parameterisations of anthropogenic heat flux $\left(Q_{F}\right)$ and storage heat flux $\left(\Delta Q_{S}\right)$ impact the turbulent fluxes (Karsisto et al., 2015). Similar values of the latent heat flux RMSE normalized with mean observed values have been found in other studies giving 90-160\% for Vancouver and Los Angeles (Järvi et al., 2011) and $130 \%$ and $70 \%$ for London and Swindon, respectively (Ward et al., 2016b). These results are at the better half of the model performances reported in the urban land surface model inter-comparison study (Grimmond et al., 2011). Deviations between the modelled output and observations are also caused by the other uncorrected meteorological variables.

However, in London the modelled cumulative evaporation with uncorrected WFDEI data is $36 \%$ larger than the measured one $\left(188 \mathrm{~mm} \mathrm{y}^{-1}\right)$. The higher modelled values can be explained by the proximity of the River Thames to the EC measurements (Ward et al., 2016b). The surface forcing used in SUEWS is calculated for the source area of the measurements leading to an open water fraction of $14 \%$. This causes high evaporation rates, but the river itself does not affect the observations as much partly because potential internal boundary layers forming over the water surface do not develop to the height of the EC tower (Kotthaus and Grimmond, 2014b). The BCQM correction improves the model results and the overestimation of the evaporation decreases to 31 $\%$. The modelled evaporation of the control run is closer to the observed values, with an overestimation of $23 \%$. Although the BCQM correction improves the RMSE, decreasing it from 0.0380 to $0.0363 \mathrm{~mm} \mathrm{~h}^{-1}$ (113\% to $108 \%$ of average hourly evaporation), with observed forcing the RMSE is only $0.0294 \mathrm{~mm} \mathrm{~h}^{-1}$ (88\% of average).

\section{Conclusions}

Urban hydrological and land surface models require fine-scale meteorological data as forcing. However, as these can be locally unavailable for the modelled period and/or at the required resolution, reanalysis may provide the required data for hydrological modelling in urban environments. Although reanalysis data are available for the larger areas in which cities are embedded, some corrections are required to use them as realistic forcing, especially in complex terrain.

Here the WFDEI reanalysis data are assessed as input to an urban atmospheric and hydrologic model (SUEWS). Through sensitivity tests for two sites in Vancouver, Canada, and one site in London, UK, the effect of each meteorological variable and downscaling of precipitation in space and time is assessed. With differences in land cover and weather types the effect of WFDEI 
data on SUEWS output can be evaluated in different conditions. In each city, EC measurements of evaporation allow the model results to be assessed.

From the sensitivity tests, it is clear that precipitation has the largest impact on modelled evaporation and runoff, with RH being second. After correction for height, the other WFDEI meteorological variables have only a minor impact on modelled evaporation and runoff and their correction would likely have minimal effect on the model performance. Based on these results, only precipitation is corrected using bias correction in this study.

The WFDEI/GPCC precipitation gives larger values than local observations. The greater difference in Vancouver than London is likely caused by greater changes in orography, particularly the mountains within the reanalysis grid. Deviations of the other WFDEI meteorological variables from observed values are smaller. Overestimation of precipitation causes larger evaporation and runoff values compared to the control run (results using observed forcing data) especially in Vancouver. Following correction of the WFDEI precipitation rates using bias correction with quantile mapping (BCQM), the modelled evaporation and runoff results are more similar to the results of the control run. However, precipitation is overestimated at the studied sites, which is probably explained by the limited amount of observations. This causes sampling errors, particularly in the upper tail of the bias corrected distribution. Also the use of moving window when estimating biases in WFDEI data set can lead to artificial biases.

In order to utilise the BCQM in other cities and sites, long observational time series in the order of 30 years with daily resolution for robust calibration and validation of the mapping are needed. Such observations are likely to exist at least in the vicinity of the city of interest (e.g. from the airports). Despite the BCQM correction method needing parameter tuning, the sensitivity tests in the studied sites show the effect of these parameters being small and fine-tuning of the parameters is not vital. Furthermore, BCQM assumes a stationary bias between the observed and reanalysis precipitation, which may be inappropriate if the calibration data are many years from the application period. When suitable daily precipitation observations exist, BCQM correction decreases the bias in WFDEI precipitation significantly and so improves the usability of the reanalysis data in hydrological modelling when observed forcing data are not available. WFDEI forcing data with BCQM correction applied to the precipitation can be used relatively reliably to model urban hydrology and land surface processes at the local scale, especially if daily-scale temporal variations are not of interest. The correction is equally applicable to downscale future projections of global or regional climate model data for urban areas or to be used with other reanalysis datasets than WFDEI. The correction is also equally applicable for other than urban areas.

As the BCQM correction brings the model results with reanalysis data closer to the control run, it indicates the removal of the first deviation, which is the interest of this study. However, the BCQM correction increases the underestimation of evaporation and does not improve the results assessed by observed evaporation. This is thought to be related to the parameterisation of the model rather than the meteorological data. As the error due to the model parameterisation surpasses the bias in WFDEI data, the parameterisation of surface land models, in addition to downscaling methods, is one of the most critical areas to improve to obtain better results from urban land surface and hydrological models. The BCQM correction in general decreases the higher values of modelled evaporation (4-15\%) and the difference of modelled runoff (0-24\%) when compared to the control run, but also brings the hourly RMSE of the modelled evaporation closer to the EC observations. Thus, the BCQM correction decreases the hourly RMSE and the bias of SUEWS' results when compared to the control run at all sites indicating that scaling precipitation to an urban area is highly relevant.

\section{Acknowledgements}

We thank Maj and Tor Nessling Foundation for funding (grant numbers 201400502, 201500273, 201600458). We also thank the Academy of Finland (ICOS-Finland 281255), the Academy of Finland Centre of Excellence (project number 1118615), the EU emBRACE (Grant number 283201), NERC/Belmont TRUC (NE/L008971/1, G8MUREFU3FP-2201-075) and Newton Fund/Met Office CSSP-China. We thank Vilho, Yrjö and Kalle Väisälä foundation for funding. Measurements at Vancouver-Sunset were financially supported by the Canadian Foundation for Climate and Atmospheric Sciences (CFCAS) as part of the Network 'Environmental Prediction in Canadian Cities' (EPiCC), by NSERC (RGPIN 342029-12), the Canadian Foundation for Innovation (CFI) (Grant numbers 17141 and 33600) as well as by BC Hydro (in-kind). London measurements were financially supported by EUFP7 Grant agreement no. 211345 (BRIDGE) and NERC ClearfLo (NE/H003231/1) and King's College London is acknowledged for hosting the measurement sites. We acknowledge Eric Leinberger for making Figure 1. We acknowledge the City of Vancouver for providing historical photographs, maps and assessment data of the study areas.

For SUEWS manual and availability: http://urban-climate.net/umep/SUEWS

\section{References}

Alexander, P. J, Mills, G. and Fealy, R. (2015), Using LCZ data to run an urban energy balance model, Urban Clim., 13, 14-37, doi:10.1016/j.uclim.2015.05.001.

Bastola, S. and Misra, V. (2014), Evaluation of dynamically downscaled reanalysis precipitation data for hydrological application, Hydrol. Process., 28, 1989-2002, doi:10.1002/hyp.9734.

Best, M. J. and Grimmond, C. S. B. (2013), Analysis of the seasonal cycle within the first international urban land surface model comparison, Bound.-Lay. Meteorol., 146, 421-446, doi:10.1007/s10546-012-9769-7.

Best, M. J. and Grimmond, C. S. B. (2014), Key conclusions of the first international urban land surface model comparison, B. Am. Meteorol. Soc., doi:http://dx.doi.org/10.1175/BAMS-D-14-00122.1. 
Best, M. J. and Grimmond, C. S. B. (2016), Modelling the partitioning of turbulent fluxes at urban sites with varying vegetation cover, $J$. Hydrometeorol., 17, 2537-2553, http://dx.doi.org/10.1175/JHM-D-15-0126.1.

Brisson, E., Van Weverberg, K., Demuzere, M., Devis, A., Saeed, S., Stengel, M. and Van Lipzig, N. P. M. (2016), How well can a convectionpermitting climate model reproduce decadal statistics of precipitation, temperature and cloud charasteristics?, Clim. Dynam., 47, pp. 30433061, doi:10.1007/s00382-016-3012-z.

Brunsdon, C., McClatchey, J. and Unwin, D. J. (2001), Spatial variations in the average rainfall-altitude relationship in Great Britain: An approach using geographically weighted regression, Int. J. Climatol., 21, 455-466, doi:10.1002/joc.614.

Christen, A., Coops N. C., Crawford B. R., Kellett R., Liss K. N., Olchovski I., Tooke T. R., van der Laan M., Voogt J. A. (2011), Validation of modeled carbon-dioxide emissions from an urban neighborhood with direct eddy-covariance measurements, Atmos. Environ., 45, 60576069, http://dx.doi.org/10.1007/s00382-016-3012-z.

Dee, D. P., Uppala, S. M., Simmons, A. J., Berrisford, P., Poli, P., Kobayashi, S., Andrae, U., Balmaseda, M. A., Balsamo, G., Bauer, P., Bechtold, P., Beljarrs, A. C. M., van de Berg, L., Bidlot, J., Bormann, N., Delsol, C., Dragani, R., Fuentes, M., Geer, A. J., Haimberger, L., Healy, S. B., Hersbach, H., Hólm, E. V., Isaksen, L., Kallberg, P., Köhler, M., Matricardi, M., McNally, A. P., Monge-Sanz, B. M., Morcrette, J.-J., Park, B.-K., Peubey, C., de Rosnay, P., Tavolato, C., Thépaut, J.-N. and Vitart, F. (2011), The ERA-Interim reanalysis: Configuration and performance of the data assimilation system, Q. J. Roy. Meteor. Soc., 137, 553-597, http://dx.doi.org/10.1002/qj.828.

Dosio, A. and Paruolo, P. (2011), Bias correction of the ENSEMBLES high-resolution climate change projections for use by impact models: Evaluation on the present climate, J. Geophys. Res., 116, D16106, doi:10.1029/2011JD015934.

Environment Canada (2015), Meteorological data from Vancouver International Airport, url: http://climate.weather.gc.ca/index_e.html, accessed 6 May 2015.

Fowler, H. J., Blenkinsop, S. and Tebaldi, C. (2007), Linking climate change modelling to impacts studies: recent advances in downscaling techniques for hydrological modelling, Int. J. Climatol., 27, 1547-1578, doi:10.1002/joc.1556.

Frei, C., Christensen, J. H., Déqué, M., Jacob, D., Jones, R. G. and Vidale, P. L. (2003), Daily precipitation statistics in regional climate models: Evaluation and intercomparison for the European Alps, J. Geophys. Res., 108(D3), 4124, doi:10.1029/2002JD002287.

Greater London Authority (2015), Daytime population, Borough, url: https://files.datapress.com/london/dataset/daytime-populationborough/2015-10-08T10:09:51/daytime-population-borough.xls, created 25 Nov 2013, modified 7 Oct 2015, accessed 1 Mar 2016.

Grimmond, C. S. B. and Oke, T. R. (1986), Urban water balance 2: results from a suburb of Vancouver, British Columbia, Water Resources Research, 22, 1404-1412, http://dx.doi.org/10.1029/WR022i010p01404.

Grimmond, C. S. B. and Oke, T. R. (1991), An evapotranspiration-interception model for urban areas, Water Resour. Res., 27, 1739-1755, http://dx.doi.org/10.1029/91WR00557.

Grimmond, C. S. B., Cleugh, H. A. and Oke, T. R. (1991), An objective urban heat-storage model and its comparison with other schemes, Atmos. Environ., 25, 311-326, doi:10.1016/0957-1272(91)90003-w.

Grimmond, C. S. B., Best, M., Barlow, J., Arnfield, A. J., Baik, J.-J., Baklanov, A., Belcher, S., Bruse, M., Calmet, I., Chen, F., Clark, P., Dandou, A., Erell, E., Fortuniak, K., Hamdi, R., Kanda, M., Kawai, T., Kondo, H., Krayenhoff, S., Lee, S. H., Limor, S.-B., Martilli, A., Masson, V., Miao, S., Mills, G., Moriwaki, R., Oleson, K., Porson, A., Sievers, U., Tombrou, M., Voogt, J. and Williamson, T. (2009), Urban surface energy balance models: model characteristics and methodology for a comparison study. In: Baklanov, A. , Grimmond, S., Mahura, A. and Athanassiadou, M. (eds.) Meteorological and Air Quality Models for Urban Areas. Springer, pp. 97-123, ISBN 9783642002977, 10.1007/978-3-642-00298-4_11.

Grimmond, C. S. B, Blackett, M., Best, M. J., Barlow, J., Baik, J.-J., Belcher, S. E., Bohnenstengel, S. I., Calmet, I., Chen, F., Dandou, A., Fortuniak, K., Gouvea, M. L., Hamdi, R., Hendry, M., Kawai, T., Kawamoto, Y., Kondo, H., Krayenhoff, E. S., Lee, S.-H., Loridan, T., Martilli, A., Masson, V., Miao, S., Oleson, K., Pigeon, G., Porson, A., Ryu, Y.-H., Salamanca, F., Shashua-Bar, L., Steeneveld, G.-J., Trombou, M., Voogt, J., Young, D. and Zhang, N. (2010a), The international urban energy balance models comparison project: first results from phase 1, J. Appl. Meteorol. Clim., 49, 1268-1292, doi:10.1175/2010JAMC2354.1.

Grimmond, C. S. B, Roth, M., Oke, T. R., Au, Y. C., Best, M., Betts, R., Carmichael, G., Cleugh, H., Dabberdt, W., Emmanuel, R., Freitas, E., Fortuniak, K., Hanna, S., Klein, P., Kalkstein, L. S., Liu, C. H., Nickson, A., Pearlmutter, D., Sailor, D. and Voogt, J. (2010b), Climate and more sustainable cities: climate information for improved planning and management of cities (producers/capabilities perspective), Procedia Environ. Sci., 1, 247-274, http://dx.doi.org/10.1016/j.proenv.2010.09.016.

Grimmond, C. S. B., Blackett, M., Best, M. J., Baik, J.-J., Belcher, E., Beringer, J., Bohnenstengel, S. I., Calmet, I., Chen, F., Coutts, A., Dandou, A., Fortuniak, K., Gouvea, M. L., Hamdi, R., Hendry, M., Kanda. M., Kawai, T., Kawamoto, Y., Kondo, H., Krayenhoff, E. S., Lee, S.-H., Lorida, T., Martilli, A., Masson, V., Miao, S., Oleson, K., Ooka, R., Pigeon, G., Porson, A., Ryu, Y.-H., Salamanca, F., Steeneveld, G. J., Tombrou, M., Voogt, J. A., Young, D. T. and Zhang, N. (2011), Initial results from Phase 2 of the international urban energy balance model comparison, Int. J. Climatol., 31, 244-272, doi: 10.1002/joc.2227.

Gudmundsson, L., Bremnes, J., Haugen, J. and Engen-Skaugen, T. (2012), Technical note: Downscaling RCM precipitation to the station scale using statistical transformations-A comparison of methods, Hydrol. Earth Syst. Sc., 16, 3383-3390, doi:10.5194/hess-16-3383-2012.

Harris, I., Jones, P. D., Osborn, T. J. and Lister, D. H. (2013), Updated high-resolution grids of monthly climatic observations - the CRU TS3.10 Dataset, Int. J. Climatol., 34, 623-642, doi:10.1002/joc.3711.

Holloway, C. E., Petch, J. C., Beare, R. J., Bechtold, P., Craig, G. C., Derbyshire, S. H., Donner, L. J., Field, P. R., Gray, S. L., Marham, J. H., Parker, D. J., Plant, R. S., Roberts, N. M., Schultz, D. M., Stirling, A. J. and Woolnough, S. J. (2014), Understanding and representing atmospheric convection across scales: recommendations from the meeting held at Darlington Hall, Devon, UK, 28-30 January 2013, Atmos. Sci. Lett., 15, 348-353, doi: 10.1002/as12.508.

IPCC (2014), Climate change 2014: impacts, adaptation, and vulnerability. Part A: Global and sectoral aspects. In: Field, C. B., Barros, V. R., Dokken, D. J., Mach, K. J., Mastrandrea, P.R., White, L. L., (Eds.), Contribution of Working Group II to the Fifth Assessment Report of the Intergovernmental Panel on Climate Change. Cambridge University Press, Cambrige, United Kingdom and New York, NY, USA, 1132 p.

Järvi, L., Grimmond, C. S. B. and Christen, A. (2011), The Surface Urban Energy and Water Balance Scheme (SUEWS): Evaluation in Los Angeles and Vancouver, J. Hydrol., 411, 219-237, http://dx.doi.org/10.1016/j.jhydrol.2011.10.001.

Järvi, L., Grimmond, C. S. B., Taka, M., Nordbo, A., Setälä, H. and Strachan, I. (2014), Developments of the Surface Urban Energy and Water balance Scheme (SUEWS) for cold climate cities. Geosci. Mod. Dev. 7, 1691-1711, doi:10.5194/gmd-7-1691-2014.

Karsisto P., Fortelius C., Demuzere M., Grimmond C.S.B., Oleson K., Kouznetsov R., Masson V. and Järvi L. (2015), Seasonal surface urban energy balance and wintertime stability simulated using three land-surface models in the high-latitude city Helsinki. Q. J. Roy. Meteor. Soc., 142 (694), 401-417, doi:10.1002/qj.2659.

Kalnay, E., Kanamitsu, M., Kistler, R., Collins, W., Deaven, D., Gandin, L., Iredell, M., Saha, S., White, G., Woollen, J., Zhu, Y., Chell iah, M., Ebisuzaki, W., Higgins, W., Janowiak, J., Mo, K. C., Ropelewski, C., Wang, J., Leetmaa, A., Reynolds, R., Jenne, R. and Joseph, D. (1996), The NCEP/NCAR 40-year reanalysis project, B. Am. Meteorol. Soc., 77, 437-470, http://dx.doi.org/10.1175/15200477(1996)077b0437:TNYRPN2.0.CO;2. 
Kanamitsu, M. and Kanamaru, H. (2007), Fifty-seven-year California reanalysis downscaling at 10 km (CaRD10). Part I: System detail and validation with observations, J. Climate, 20, 5553-5571, doi:0.1175/2007JCLI1482.1.

Kellett, R., Christen, A., Coops, N. C., van der Laan, M., Crawford, B., Tooke, T. R. and Olchovski, I. (2013), A systems approach to carbon cycling and emissions modeling at an urban neighborhood scale, Landscape urban plan., 110, 48-58, doi:10.1016/j.landurbplan.2012.10.002.

Knight, R. R. and Cuffney, T. F. (2012), Invertebrate response to changes in streamflow hydraulics in two urban areas in the United States, U.S. Geol. Surv. Sci. Investig. Rep. 2012-5035, 19 p.

Kobayashi, S., Ota, Y., Harada, Y., Ebita, A., Moriya, M., Onoda, H., Onogi, K., Kamahori, H., Kobayashi, C., Endo, H., Miyaoka, K. and Takahashi, K. (2015), The JRA-55 reanalysis: General specifications and basic characteristics, J. Meteorol. Soc. Japan, 93, 5-48, doi: 10.2151/jmsj.2015-001.

Konrad, C. P. and Booth, D. B. (2002), Hydrological trends resulting from urban development in a western Washington stream, U.S. Geol. Surv. Water-Resour. Investig. Rep. 02-4040, 40 p.

Kotthaus, S. and Grimmond, C. S. B. (2014a), Energy exchange in a dense urban environment - Part I: Temporal variability of long-term observations in central London, Urban Clim., 10, part 2, 261-280, doi:10.1016/j.uclim.2013.10.002.

Kotthaus, S. and Grimmond, C. S. B. (2014b), Energy exchange in a dense urban environment - Part II: Impact of spatial heterogeneity of the surface, Urban Clim., 10, part 2, 281-307, doi:10.1016/j.uclim.2013.10.001.

Loridan, T., Grimmond, C. S. B., Offerle, B. D., Young, D. T., Smith, T. E. L., Järvi, L. and Lindberg, F. (2011), Local-Scale Urban Meteorological Parameterization Scheme (LUMPS): Longwave Radiation Parameterization and Seasonality-Related Developments, J. Appl. Meteorol. Clim., 50, 185-202, doi:10.1175/2010jamc2474.1.

Loridan, T. and Grimmond, C. S. B. (2012), Multi-site evaluation of an urban land-surface model: intra-urban heterogeneity, seasonality and parameter complexity requirements, Q. J. Roy. Meteor. Soc., 138 (665), pp. 1094-1113, doi: 10.1002/qj.963.

Mapzen (2016), Metro Extracts, https://mapzen.com/data/metro-extracts/, accessed January 2017.

Met Office (2015), Meteorological data from Met Office, url: http://badc.nerc.ac.uk/data/, accessed 17 November 2015.

Met Office (2016), Southern England: climate, url: http://www.MetOffice.gov.uk/climate/uk/regional-climates/so, accessed 10 May 2016.

Mitchell, V. G., Mein, R. G. and McMahon, T. A. (2001), Modelling the urban water cycle, Environ. Modell. Softw., 16, 615-629, http://dx.doi.org/10.1016/S1364-8152(01)00029-9.

Mitchell, V. G., McMahon, T. A. and Mein, R. G. (2003), Components of the total water balance of an urban catchment, Environ. Manage., 32, 735-746, http://dx.doi.org/10.1007/s00267-003-2062-2.

Nordbo, A., Karsisto, P., Matikainen, L., Wood, C. and Järvi, L. (2015), Urban surface cover determined with airborne lidar at $2 \mathrm{~m}$ resolution implications for surface energy balance modelling, Urban Clim., 13, 52-72, doi:10.1016/j.uclim.2015.05.004.

Offerle, B., Grimmond, C. S. B. and Oke, T. R. (2003), Parameterization of net all-wave radiation for urban areas, J. Appl. Meteorol., 42, 11571173, doi:10.1175/1520-0450(2003)042;1157:ponarf;2.0.co;2.

Oke, T. and Hay, J. (1994), The Climate of Vancouver, no 50 in B. C. geographical series, $2^{\text {nd }}$ ed., Department of Geography, University of British Columbia.

Paul, M. J. and Meyer, J. L. (2001), Streams in the urban landscape, Annu. Rev. Ecol. Syst., 32, 333-365.

Piani, C., Weedon, G. P., Best, M., Gomes, S. M., Viterbo, P., Hagemann, S. and Haerter, J. O. (2010), Statistical bias correction of global simulated daily precipitation and temperature for the application of hydrological models, J. Hydrol., 395, 199-215, doi: 10.1016/j.jhydrol.2010.10.024.

Rienecker, M. M., Suarez, M. J., Gelaro, R., Todling, R., Bacmeister, J., Liu, E., Bosilovich, M. G., Schubert, S. D., Takacs, L., Kim, G.-K., Bloom, S., Chen, J., Collins, D., Conaty, A., da Silva, A., Gu, W., Joiner, J., Koster, R. D., Lucchesi, R., Molod, A., Owens, T., Pawson, S., Pegion, P., Redder, C. R., Reichle, R., Robertson, F. R., Ruddick, A. G., Sienkiewicz, M. and Woollen, J. (2011), MERRA: NASA's modern-era retrospective analysis for research and applications, J. Clim., 24, 3624-3648, doi: 10.1175/JCLI-D-11-00015.1.

Rodriguez, F., Andrieu, H. and Creutin, J.-D. (2003), Surface runoff in urban catchments: morphological identification of unit hydrographs from urban databanks, J. Hydrol., 283, 146-168, doi:10.1016/S0022-1694(03)00246-4.

Räisänen, J. and Räty, O. (2013), Projections of daily mean temperature variability in the future: cross-validation tests with ENSEMBLES regional climate simulations, Clim. Dynam., 41, 1553-1568, http://dx.doi.org/10.1007/s00382-012-1515-9.

Räty, O., Räisänen, J. and Ylhäisi, J. S. (2014), Evaluation of delta change and bias correction methods for future daily precipitation: intermodel cross-validation using ENSEMBLES simulations, Clim. Dynam., 42, 2287-2303, http://dx.doi.org/10.1007/s00382-014-2130-8.

Schneider, U., Becker, A., Finger, P., Meyer-Christoffer, A., Ziese, M. and Rudolf, B. (2013), GPCC's new land surface precipitation climatology based on quality-controlled in situ data and its role in quantifying the global water cycle, Theor. Appl. Climatol., 115, 15-40, doi:10.1007/s00704-013-0860-x.

Stewart, I. D., and Oke, T. R. (2012), Local Climate Zones for Urban Temperature Studies, B. Am. Meteorol. Soc., 93 (12), 1879-1900, doi:10.1175/BAMS-D-11-00019.1.

Sun, F., Roderick, M. L., Lim, W. H. and Farquhar, G. D. (2011), Hydroclimatic projections for the Murray-Darling Basin based on an ensemble derived from Intergovernmental Panel on Climate Change AR4 climate models, Water Resour. Res., 47, p. W00G02, http://dx.doi.org/10.1029/2010WR009829.

Sunyer, M. A., Hundecha, Y., Lawrence, D., Madsen, H., Willems, P., Martinkova, M., Vormoor, K., Bürger, G., Hanel, M., Kriaučlūnienė, J., Loukas, A., Osuch, M. and Yücel, I. (2015), Inter-comparison of statistical downscaling methods for projection of extreme precipitation in Europe, Hydrol. Earth Syst. Sc., 19, 1827-1847, doi:10.5194/hess-19-1827-2015.

Teutschbein, C. and Seibert, J. (2012), Bias correction of regional climate model simulations for hydrological climate-change impact studies: Review and evaluation of different methods, J. Hydrol., 456-457, 12-29, doi:10.1016/j.jhydrol.2012.05.052.

Ward, H. C., Järvi, L., Onomura, S., Lindberg, F., Gabey, A. and Grimmond, C. S. B. (2016a), SUEWS Manual V2016a, http://urbanclimate.net/umep/SUEWS.

Ward, H. C., Kotthaus, S., Järvi, L. and Grimmond, C. S. B. (2016b), Surface Urban Energy and Water Balance Scheme (SUEWS): development and evaluation at two UK sites. Urban Clim., 18, 1-32, http://dx.doi.org/10.1016/j.uclim.2016.05.001.

Ward, H. C. and Grimmond, C. S. B. (2017), Assessing the impact of changes in surface cover, human behaviour and climate on energy partitioning across Greater London. Landsc. Urban Plan, http://dx.doi.org/10.1016/j.landurbplan.2017.04.001.

Weedon, G. P., Balsamo, G., Bellouin, N., Gomes, S., Best, M. and Viterbo, P. (2014), The WFDEI meteorological forcing data set: WATCH Forcing Data methodology applied to ERA-Interim reanalysis data, Water Resour. Res., 50, 7505-7514.

Weedon, G. P., Gomes, S., Viterbo, P., H. Österle, J. C. A., Bellouin, N., Boucher, O. and Best, M. (2010), The WATCH Forcing Data 19582001: a meteorological forcing dataset for land surface- and hydrological models, WATCH Tech. Rep. 22.

Weedon, G. P., Gomes, S., Viterbo, P., Shuttleworth, W. J., Blyth, E., Österle, H., Adam, J. C., Bellouin, N., Boucher, O. and Best, M. (2011), Creation of WATCH Forcing Data and its use to assess global and regional reference crop evaporation over land during the twentieth century, J. Hydrometeorol., 12, 823-848, http://dx.doi.org/10.1175/2011JHM1369.1. 
Wilby, R. L., Hay, L. E., Gutowski Jr., W. J., Arrit, R. W., Takle, E. S., Pan, Z., Leavesley, G. H. and Clark, M. P. (2000), Hydrological responses to dynamically and statistically downscaled climate model output, Geophys. Res. Lett., 27, 1199-1202, doi:10.1029/1999GL006078.

Wood, A. W., Leung, L. R., Sridhar, V. and Lettenmaier, D. P. (2004), Hydrologic implications of dynamical and statistical approaches to downscaling climate model outputs, Climatic Change, 62, 189-216, http://dx.doi.org/10.1023/B:CLIM.0000013685.99609.9e.

Wouters, H., Demuzere, M., De Ridder, K. and van Lipzig N. P. M. (2015), The impact of impervious water-storage parametrization on urban climate modelling, Urban Clim., 11, 24-50, http://dx.doi.org/10.1016/j.uclim.2014.11.005.

Table 1. Characteristics of the study sites. Data from Järvi et al. (2011) and Ward et al. (2016b).

\begin{tabular}{|c|c|c|c|}
\hline City & Vancouver & & London \\
\hline & Oakridge & Sunset & Westminster \\
\hline Year & 1982 & 2009 & 2012 \\
\hline DOY & $22-365$ & $1-365$ & $1-366$ \\
\hline Code & Vo82 & Vs09 & Lo12 \\
\hline Location & $\begin{array}{l}49^{\circ} 13^{\prime} 29^{\prime \prime} \mathrm{N}, \\
123^{\circ} 7^{\prime} 57^{\prime \prime} \mathrm{W}\end{array}$ & $\begin{array}{l}49^{\circ} 13^{\prime} 26^{\prime \prime N}, \\
123^{\circ} 5^{\prime} 6^{\prime \prime} \mathrm{W}\end{array}$ & $\begin{array}{l}51^{\circ} 30^{\prime} 42^{\prime \prime} \mathrm{N}, \\
0^{\circ} 66^{\prime} 59^{\prime \prime} \mathrm{W}\end{array}$ \\
\hline$A$ (ha) & 21 & 78 & 78.5 \\
\hline$f_{\text {bldg }}$ & 0.19 & 0.23 & 0.38 \\
\hline$f_{\text {pav }}$ & 0.25 & 0.45 & 0.43 \\
\hline$f_{\text {evergr }}$ & 0.04 & 0.03 & 0.00 \\
\hline$f_{d e c}$ & 0.08 & 0.09 & 0.02 \\
\hline$f_{\text {water }}$ & 0.00 & 0.00 & 0.14 \\
\hline$f_{\text {grass }}$ & 0.44 & 0.2 & 0.03 \\
\hline$f_{\text {irrgrass }}$ & 0.75 & 0.9 & 0.00 \\
\hline faut & 0.05 & 0.01 & 0.00 \\
\hline$p_{\text {pop }}\left(\right.$ in $\left.\mathrm{ha}^{-1}\right)$ & 20.5 & 64.1 & 310.4 \\
\hline$T_{\text {zone }}$ & GMT-8 & GMT-8 & GMT \\
\hline$z h(\mathrm{~m})$ & 7 & 5.5 & 22.0 \\
\hline$z h v(\mathrm{~m})$ & 7 & 7.1 & 13.1 \\
\hline
\end{tabular}

Year: year of sensitivity tests model run, DOY: day of the year, Code: short name for the site, $A$ : modelled area, $f_{b l d g}$ : plan area fraction of buildings, $f_{\text {pav }}$ : plan area fraction of paved surfaces, $f_{\text {evergr }}$ : plan area fraction of evergreen trees and shrubs, $f_{\text {dec }}$ : plan area fraction of deciduous trees and shrubs, $f_{\text {water: }}$ plan area fraction of open water, $f_{\text {grass }}$ : plan area fraction of grass, $f_{\text {irrgrass: }}$ : fraction of grass that is irrigated, $f_{\text {aut }}$ : fraction of automatic irrigation, $p_{p o p}$ : the population density, $T_{z o n e}$ : time zone, $z h$ and $z h v$ : mean building and vegetation height.

Table 2. Metrics obtained from comparing 60 min measured and modelled evaporation for Vancouver-Sunset in 2009 (Vs09, n=6961) and London in 2012 (Lo12, n=5598) with different smoothing parameter values ( $a$, eqn 2 ) and moving windows ( $W$, eqn 1$)$ of the BCQM correction of precipitation: root mean square error (RMSE, $\mathrm{mm} \mathrm{h}^{-1}$ ), mean absolute difference (MAE, $\mathrm{mm} \mathrm{h}^{-1}$ ) and absolute difference of cumulative values

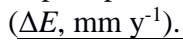

\begin{tabular}{|c|c|c|c|c|c|c|}
\hline \multirow[b]{2}{*}{$a$} & \multicolumn{3}{|l|}{ Vs09 } & \multicolumn{3}{|l|}{ Lo12 } \\
\hline & RMSE & MAE & $\Delta E$ & RMSE & MAE & $\Delta E$ \\
\hline 0.00 & 0.03519 & 0.02746 & 15.2 & 0.03634 & 0.02630 & 58.2 \\
\hline 0.01 & 0.03527 & 0.02746 & 14.9 & 0.03643 & 0.02635 & 58.5 \\
\hline 0.02 & 0.03524 & 0.02744 & 14.8 & 0.03640 & 0.02633 & 58.4 \\
\hline 0.03 & 0.03523 & 0.02744 & 14.8 & 0.03642 & 0.02633 & 58.4 \\
\hline 0.04 & 0.03515 & 0.02742 & 15.2 & 0.03643 & 0.02632 & 58.4 \\
\hline 0.05 & 0.03517 & 0.02742 & 14.7 & 0.03642 & 0.02632 & 58.4 \\
\hline \multicolumn{7}{|l|}{$W$} \\
\hline 21 & 0.03554 & 0.02746 & 13.3 & 0.03649 & 0.02637 & 58.7 \\
\hline 31 & 0.03536 & 0.02741 & 14.2 & 0.03648 & 0.02634 & 58.8 \\
\hline 41 & 0.03544 & 0.02746 & 13.2 & 0.03641 & 0.02630 & 58.5 \\
\hline 51 & 0.03515 & 0.02742 & 15.2 & 0.03637 & 0.02630 & 58.2 \\
\hline 61 & 0.03529 & 0.02749 & 14.2 & 0.03642 & 0.02630 & 58.2 \\
\hline 71 & 0.03529 & 0.02749 & 14.2 & 0.03641 & 0.02632 & 58.4 \\
\hline
\end{tabular}


Table 3. Metrics obtained by comparing the control run against modelled results with different reanalysis forcing data (see Figure 5): cumulative error of evaporation $\left(\Delta E, \mathrm{~mm} \mathrm{y}^{-1}\right)$ and runoff $\left(\Delta R, \mathrm{~mm} \mathrm{y}^{-1}\right)$ and percentage error from observed evaporation and runoff $(\%)$.

\begin{tabular}{|c|c|c|c|c|c|c|c|c|c|c|c|c|}
\hline & \multicolumn{4}{|c|}{ Vo82 } & \multicolumn{4}{|c|}{ Vs09 } & \multicolumn{4}{|c|}{ Lo12 } \\
\hline & $\Delta E$ & $\%$ & $\Delta R$ & $\%$ & $\Delta E$ & $\%$ & $\Delta R$ & $\%$ & $\Delta E$ & $\%$ & $\Delta R$ & $\%$ \\
\hline WFDEI raw & 84 & 15 & 464 & 26 & 65 & 21 & 559 & 39 & 23 & 6 & -25 & -4 \\
\hline WFDEI corr & 47 & 8 & 160 & 8 & 20 & 6 & 216 & 15 & 9 & 2 & -26 & -4 \\
\hline WFDEI $U$ & -5 & -1 & 5 & 0 & 0 & 0 & 0 & 0 & 12 & 3 & -4 & -1 \\
\hline WFDEI $T_{a}$ & -2 & 0 & -37 & -2 & -7 & -2 & -63 & -4 & -9 & -2 & 2 & 0 \\
\hline WFDEI $R H$ & 44 & 8 & -44 & -2 & 10 & 3 & -10 & -1 & -34 & -9 & 9 & 2 \\
\hline WFDEI $K \downarrow$ & -22 & -4 & 22 & 1 & -12 & -4 & 12 & 1 & 13 & 3 & -4 & -1 \\
\hline WFDEI pressure & -1 & 0 & 1 & 0 & 0 & 0 & 0 & 0 & 0 & 0 & 0 & 0 \\
\hline WFDEI precipitation & 102 & 18 & 483 & 27 & 82 & 26 & 559 & 39 & 55 & 14 & -39 & -7 \\
\hline BCQM precipitation & 57 & 10 & 190 & 10 & 34 & 11 & 270 & 19 & 39 & 10 & -39 & -7 \\
\hline
\end{tabular}

Table 4. Metrics obtained by comparing the observations to modelled results with different reanalysis forcing data (see Figure 5): cumulative error of evaporation $\left(\Delta E, \mathrm{~mm} \mathrm{y}^{-1}\right)$, root mean square error (RMSE, $\mathrm{mm} \mathrm{h}^{-1}$ ) and percent of error and RMSE from observed evaporation (\%).

\begin{tabular}{lllllllll}
\hline & \multicolumn{1}{l}{ Vs09 } & \multicolumn{7}{c}{ Lo12 } \\
\hline Control run & $\Delta E$ & $\%$ & RMSE & $\%$ & $\Delta E$ & $\%$ & RMSE & $\%$ \\
WFDEI raw & -54 & -18 & 0.0369 & 72 & 43 & 23 & 0.0294 & 88 \\
WFDEI corr & -9 & -3 & 0.0398 & 78 & 68 & 36 & 0.0380 & 113 \\
WFDEI $U$ & -47 & -15 & 0.0354 & 69 & 58 & 31 & 0.0363 & 108 \\
WFDEI $T_{a}$ & -56 & -18 & 0.0365 & 71 & 49 & 26 & 0.0297 & 88 \\
WFDEI $R H$ & -60 & -20 & 0.0358 & 70 & 37 & 20 & 0.0297 & 88 \\
WFDEI $K \downarrow$ & -52 & -17 & 0.0367 & 74 & 26 & 14 & 0.0296 & 88 \\
WFDEI pressure & -65 & -21 & 0.0364 & 71 & 49 & 26 & 0.0313 & 93 \\
WFDEI precipitation & -53 & -18 & 0.0369 & 72 & 43 & 23 & 0.0294 & 88 \\
BCQM precipitation & -26 & -9 & 0.0396 & 77 & 86 & 46 & 0.0382 & 114 \\
\hline
\end{tabular}

(a) Vancouver, Canada

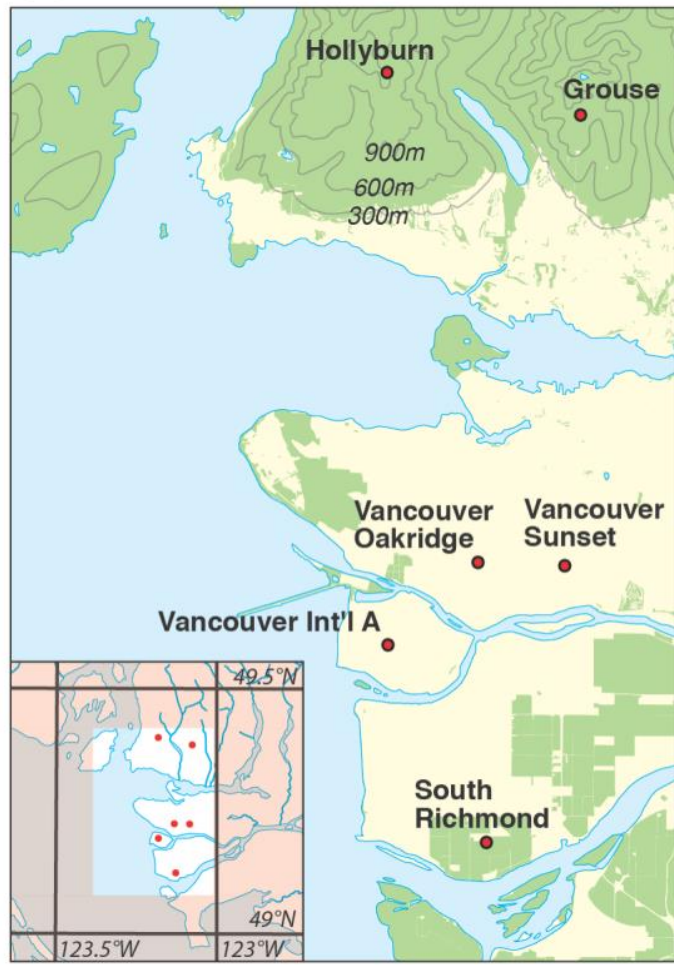

(b) London, UK

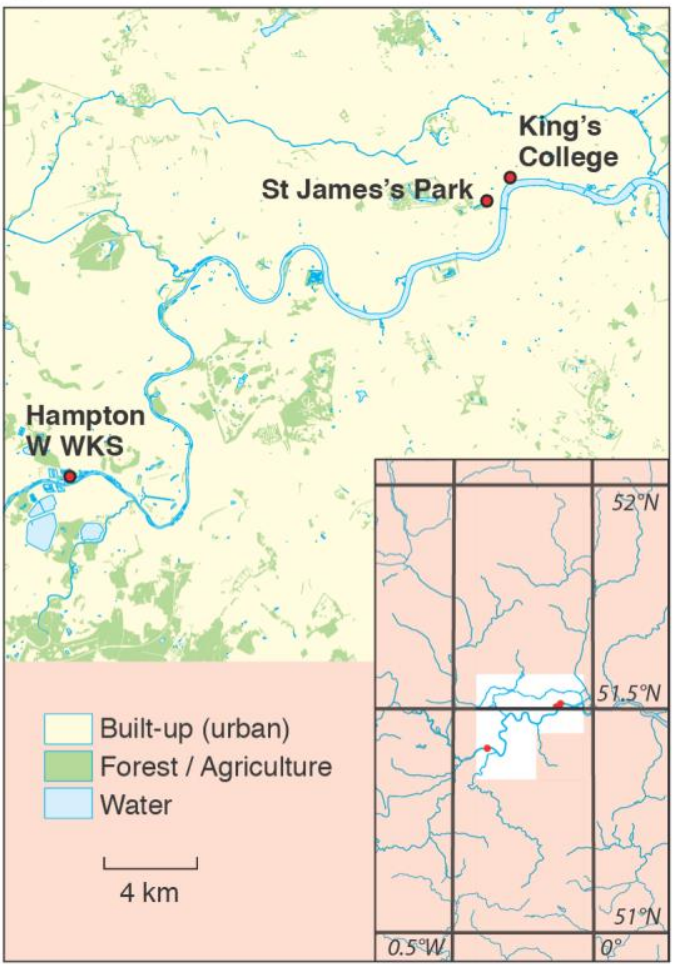

Figure 1. Map of a) Vancouver, Canada (Mapzen, 2017) and b) London, UK (Mapzen, 2017) showing locations of the study sites (VancouverOakridge (Vo82), Vancouver-Sunset (Vs09) and King's College (Lo12)) and precipitation monitoring sites (Vancouver International Airport, Hollyburn Mountain, Grouse Mountain, South Richmond, St James's Park and Hampton W WKS). Latitude and longitude lines are also locations of WFDEI grid boundaries. 

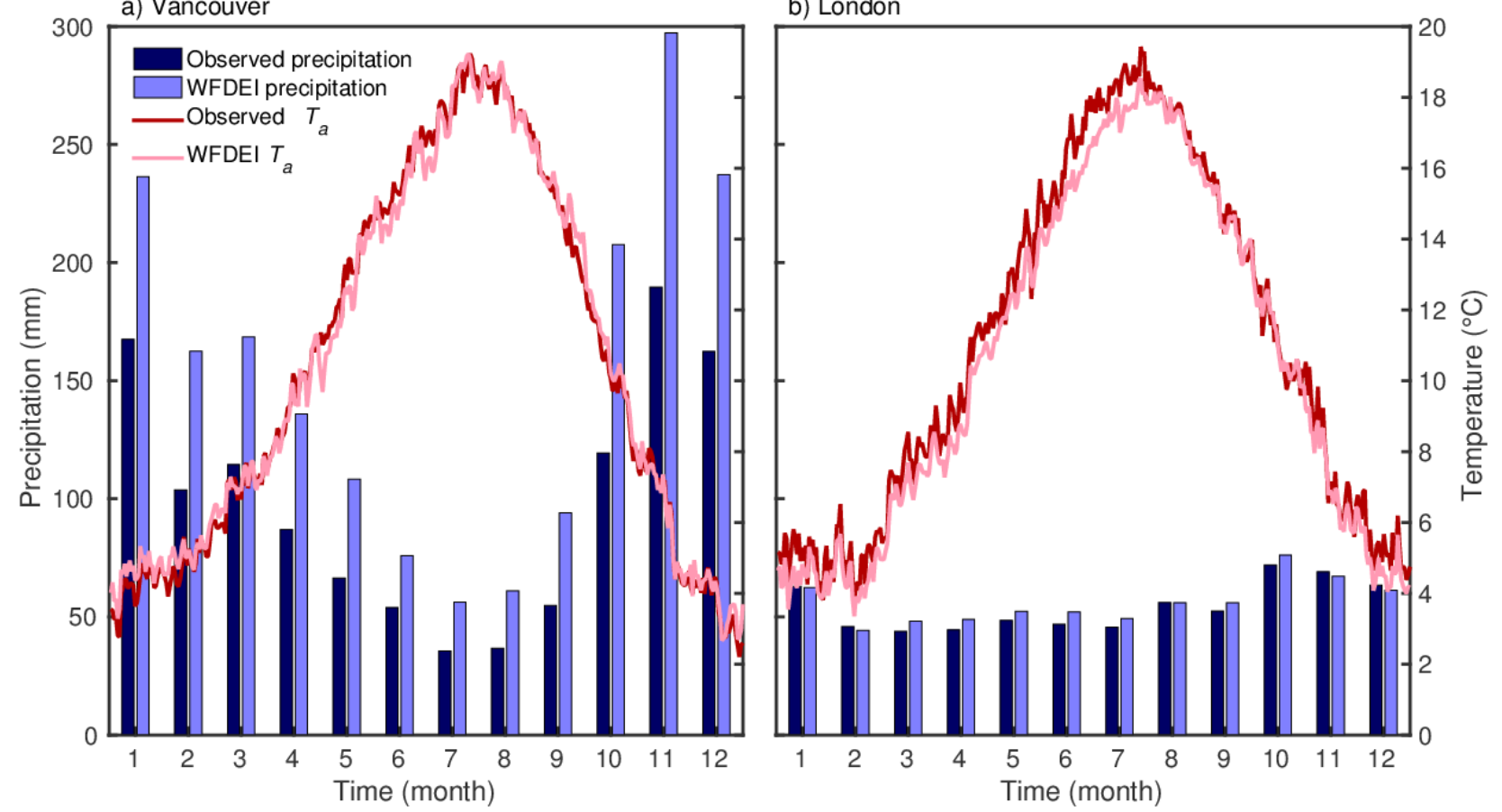

Figure 2. Normal (1981-2010) monthly precipitation (left-axis) and $2 \mathrm{~m}$ daily temperature $\left(\mathrm{T}_{\mathrm{a}}\right.$ ) (right-axis) recorded at (a) Vancouver International Airport (Environment Canada, 2015) and (b) Hampton W WKS (lat: 51.4119 N, lon: 0.37809 W, station number: 711 Met Office 2015) and the WFDEI data (Weedon et al., 2014) for the grid these sites are located in.

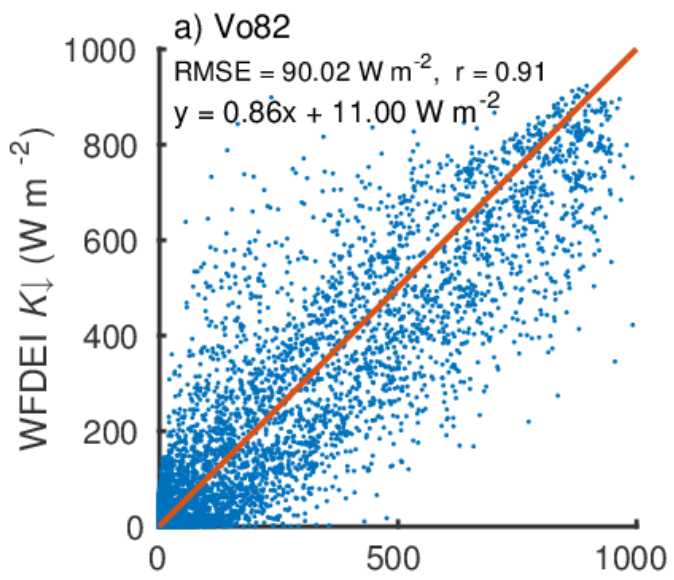

b) Vs09

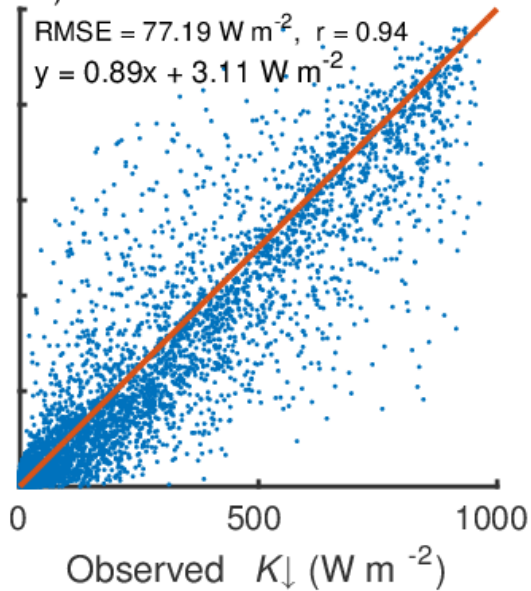

C) Lo12

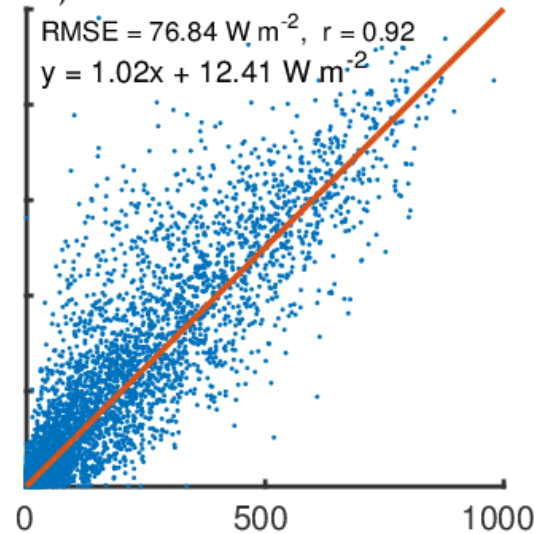

Figure 3. WFDEI incoming solar radiation $(K \downarrow)$ versus observed $K \downarrow$ at a) Vancouver-Oakridge in 1982 (Vo82), b) Vancouver-Sunset in 2009 (Vs09) and c) London in 2012 (Lo12).

\section{Precipitation of
calibration period
(observations)
Precipitation of
calibration period
(re-analysis)}

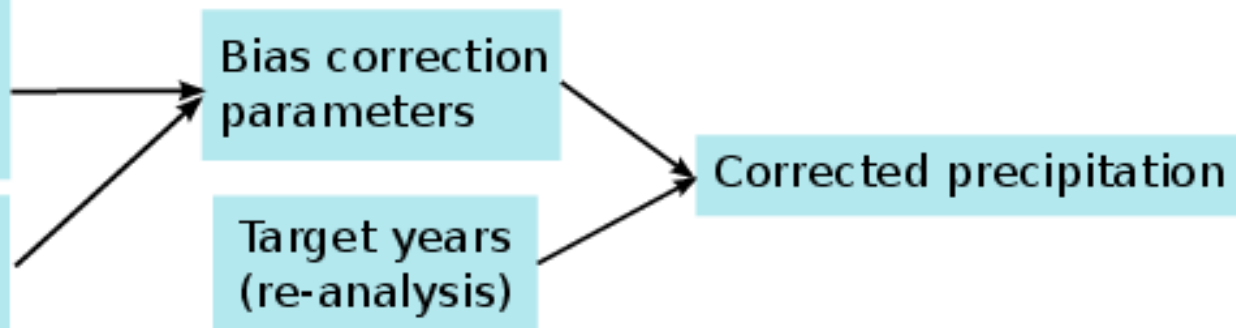

Figure 4. Flow diagram of bias correction with quantile mapping (BCQM). 

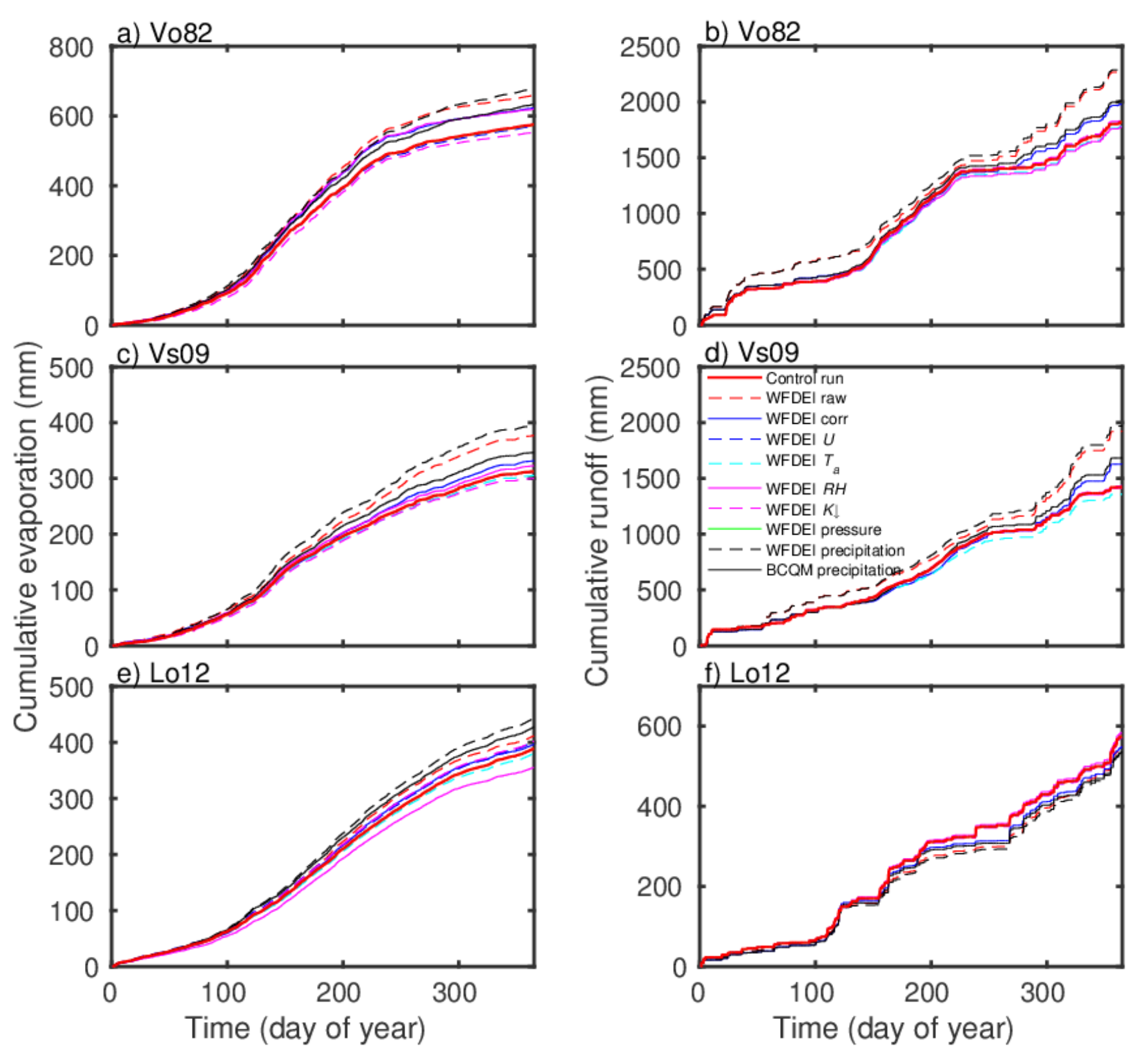

Figure 5. Modelled cumulative (a, c, e) evaporation and (b, d, f) runoff for (a, b) Vancouver-Oakridge in 1982 (Vo82), for (c, d) VancouverSunset 2009 and for (e, f) London in 2012 (Lo12) using observed forcing data (control run), uncorrected forcing data (WFDEI raw), precipitation corrected WFDEI data (WFDEI corr). The sensitivity tests with one measured meteorological variable modified in each run to the reanalysis forcing data (e.g. BCQM precipitation: has corrected reanalysis precipitation with otherwise observed forcing data). Note different scales of the y-axes. 

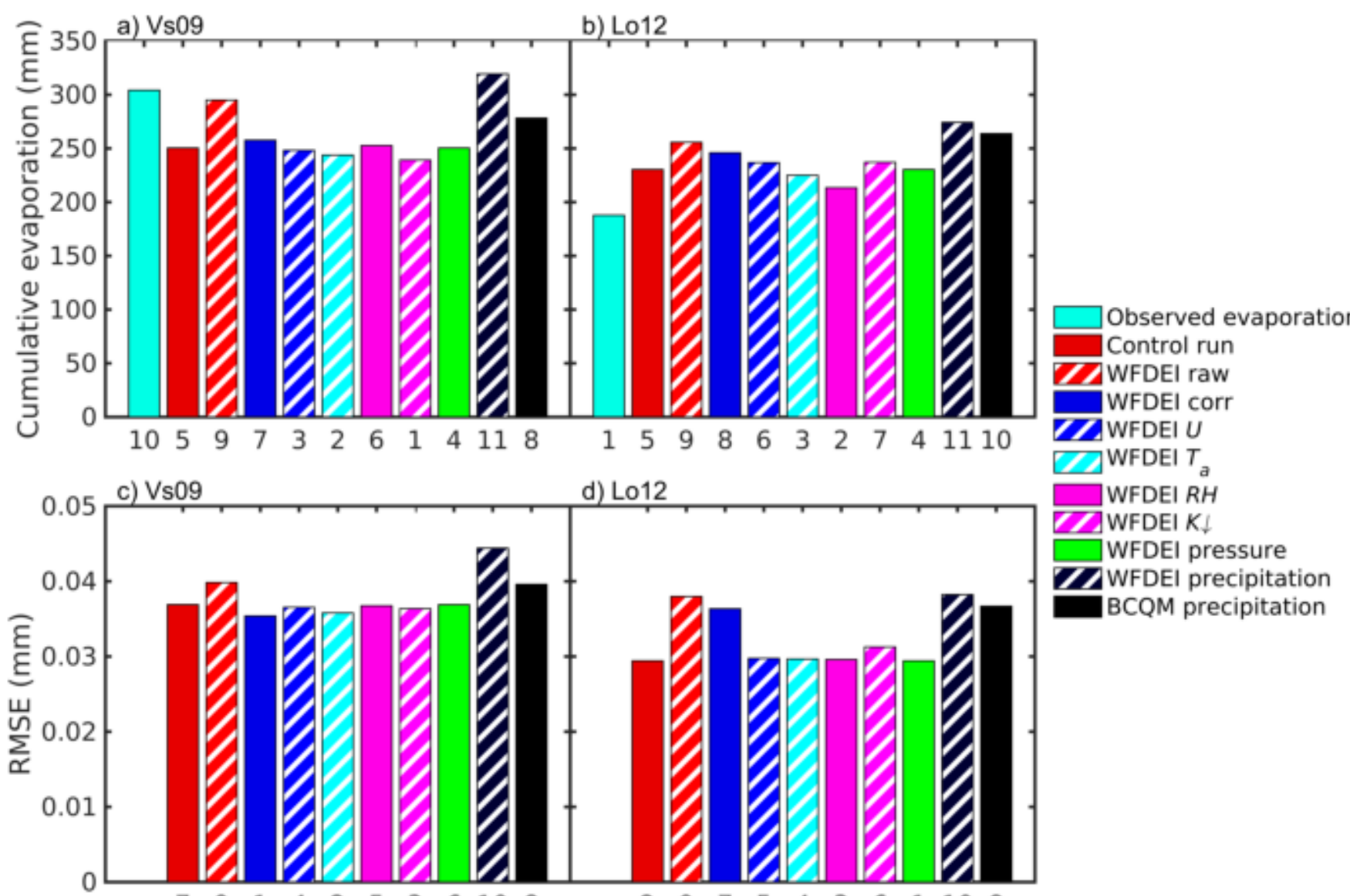

Figure 6. Observed and modelled evaporation (a, b) annual total (a) Vancouver-Sunset in 2009 (Vs09, n=6961) and (b) London in 2012 (Lo12, $\mathrm{n}=5598$ ) for all hours with direct observations of evaporation using different model forcing data (see Figure 5); (c, d) RMSE of hourly values. The ranking number from smallest to largest value is shown under the bars.

a) Vancouver

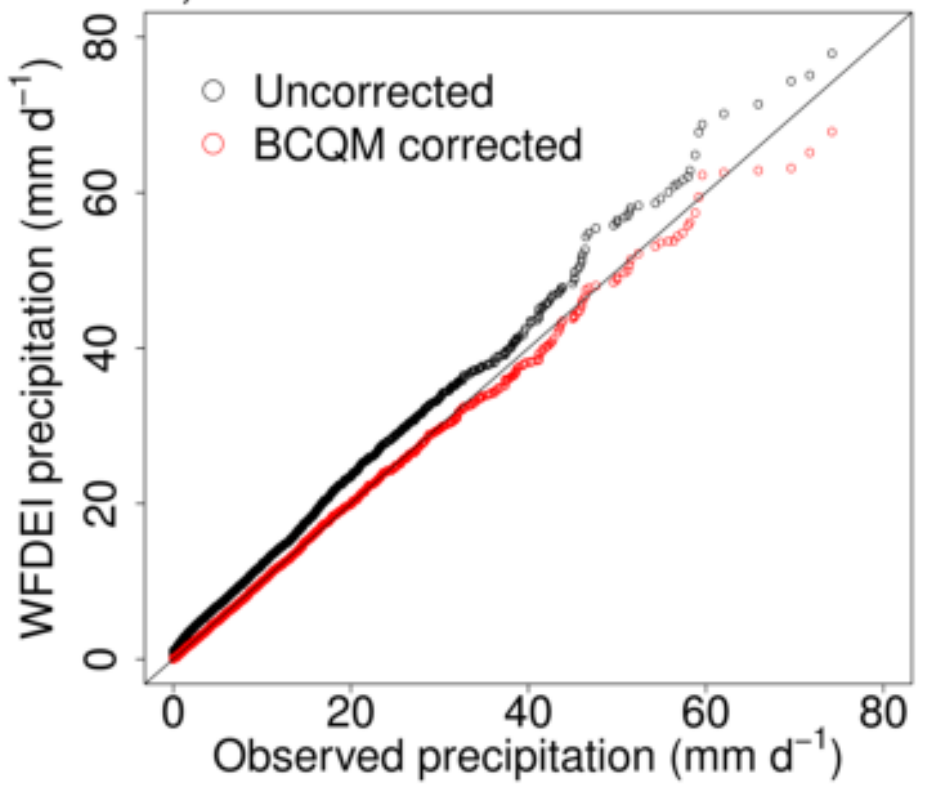

b) London

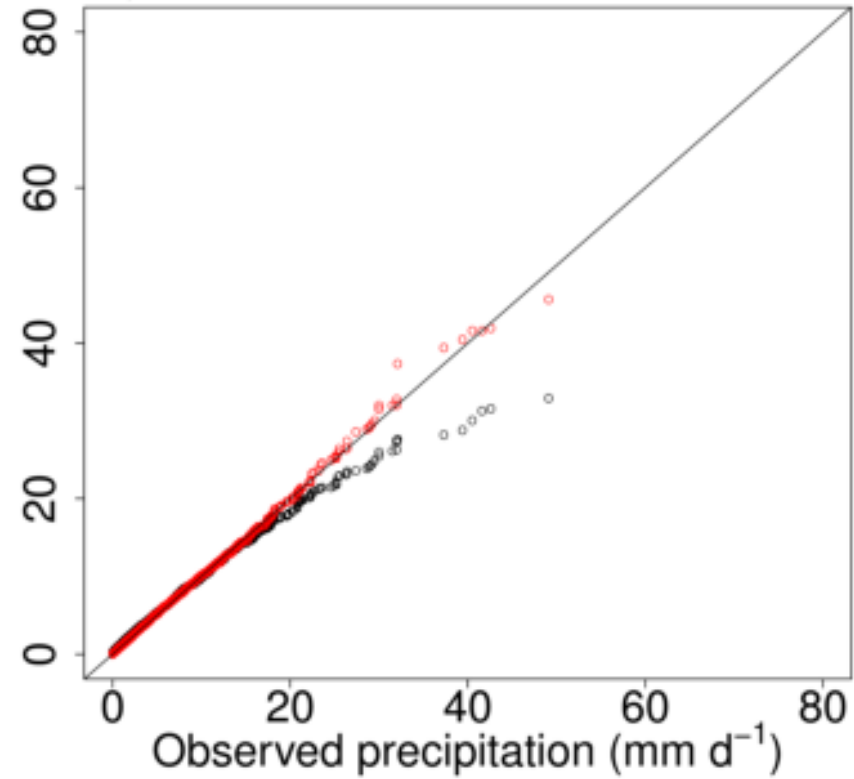

Figure 7. Quantile-quantile plots for uncorrected WFDEI precipitation (black) for 1979-2012 in a) Vancouver and b) London and BCQM corrected precipitation (red) versus observed precipitation (1990-2008 in Vancouver and 1980-2008 in London). Both Vancouver sites use the WFDEI forcing data from the same grid cell. 